\title{
Sustainability through energy efficiency: an Italian perspective ${ }^{1}$
}

\author{
Federico Testa - Vania Vigolo
}

\begin{abstract}
Purpose of the paper: Firms' efficient use of energy contributes to social, environmental and economic sustainability, as well as to their competitiveness. The discrepancy between optimal and actual implementation of energy efficiency measures has been described in literature as the 'energy efficiency gap'. Recently, some scholars have related this gap to both technology and energy management, thus introducing an 'extended energy efficiency gap'. Given these premises, this study investigates the extended energy efficiency gap from the perspective of the Italian small and medium industrial enterprises (SMEs). Specifically, it intends to identify possible solutions to overcome the major barriers to energy efficiency, in terms of technology investments and energy management.

Methodology: This is a conceptual study which adopts a solution-building approach based on literature review and secondary data analysis.

Research findings: This study proposes a framework that can be used to explore and reduce the extended energy efficiency gap for Italian industrial SMEs. The possible solutions to improve energy efficiency include distributed generation, cluster energy management, result-based economic incentives and smart grids.

Research limits: Qualitative and quantitative studies should be conducted to further investigation of the major barriers of efficiency, as perceived by SMEs. Households' and policy makers' perspectives could also be addressed in future studies.

Practical implications: This study suggests that, through collaboration, firms could improve their energy efficiency, thus increasing their economic sustainability and competitiveness. Moreover, policy makers should encourage energy efficiency through result-based incentives and the development of smart grids.

Originality of the paper: This is one of very few studies that address the extended energy efficiency gap for Italian SMEs. Additionally, it proposes a framework of analysis that takes into account the relationship between barriers and efficiency gap levels.
\end{abstract}

Key words: energy efficiency gap; technology; energy management; distributed generation; smart grids; result-based incentives

1 While the article is the result of a joint effort of the Authors, the individual contributions are as follows: Federico Testa wrote paragraph 5.2 (specifically, "Possible solutions to gap 1", "Possible solutions to gap 2", and "Possible solutions to gap 5 and gap 6"), as well as paragraphs 6 and 7. Vania Vigolo wrote paragraphs $1,2,3,4,5.1$ and 5.2 (specifically, "Possible solutions to gap 3 and gap 4"). 


\section{sinergie}

Vol. 33, N. 96, 2015

\section{Introduction}

Sustainability embraces every kind of human activity, and has profound environmental, social and economic implications (Crane, 2007; Blackburn, 2012; Boons et al., 2013; Beckmann et al., 2014). In recent decades, national and international institutions have sought to increase awareness of sustainability among individuals, firms and public organisations, setting ambitious goals regarding climate and energy. Specifically, the European Union has established the 20-20-20 targets: reducing EU's greenhouse gas emissions by $20 \%$ compared to 1990 levels; increasing the share of EU's energy consumption produced from renewable resources to 20\%; and improving EU's energy efficiency by $20 \%$. As greenhouse gas emissions are largely caused by fossil fuels, the issue of energy is vital in for the interests of sustainable growth. According to recent studies, $36.5 \%$ of the final electricity consumption in the EU derives from industry, $29.7 \%$ from households, $29.7 \%$ from service, $2 \%$ from agriculture and other sectors and $2.4 \%$ from transport (European Environment Agency, 2013). Hence, in order to increase the sustainability of energy systems, it is necessary to change the behaviour, the values and the methods of energy consumption of these subjects (Baccarani and Golinelli, 2008; Palm and Thollander, 2010). Through the Energy Efficiency Plan 2011 and the Energy Efficiency Directive, the EU proposes measures to improve energy efficiency in households, businesses and public institutions.

In the EU Directive 2006/32/EC on energy end-use efficiency and energy services, energy efficiency has been described as "a ratio between an output of performance, service, goods or energy and an input of energy" (Blomberg et al., 2012, p. 569). However, there is still discrepancy between the potential of energy efficiency and the actual energy efficiency. This difference is called the 'energy efficiency gap' (Jaffe and Stavins, 1994). Traditionally, with reference to firms, the energy efficiency gap has been attributed to a technological gap, but in a recent study, Backlund et al. (2012) emphasised that an energy management gap should also be considered.

This paper will explore possible ways to reduce the energy efficiency gap in the Italian context. In particular, the study aims to implement the extended efficiency gap model developed by Backlund et al. (2012) to Italian firms, specifically to industrial small and medium enterprises (SMEs). SMEs represent 99.9\% of total firms in Italy (European Commission, 2013). Specifically, in Italy, SMEs cover about $60 \%$ of the industrial energy consumption (Trianni et al., 2013). Therefore, investigating the energy efficiency potentialities for industrial SMEs is a priority. This is a conceptual study based upon the analysis of academic literature and secondary data provided by national and international institutions. The paper is structured as follows: research approach; analysis of the literature on energy efficiency and the energy efficiency gap; analysis of the efficiency gap in the Italian context; identification of proposals to overcome the efficiency gap; managerial implications. 


\section{Research approach}

Given the scarcity of research on how to reduce the energy efficiency gap for SMEs, this study has an exploratory nature and adopts a conceptual approach (Gill and Johnson, 1991). Specifically, this study makes a solutionbuilding contribution by providing tools and guidelines on how to solve the energy efficiency gap for Italian SMEs (Gregor, 2006). According to this approach, solutions are not empirically tested, but proposed on the basis of secondary data analyses which included a literature review of academic, practitioners' and institutional publications. In the first step, the literature review served as a way of developing a conceptual framework for exploring the energy efficiency gap. In particular, international academic publications, published in high-rank journals (e.g. indexed in Elsevier-Scopus and Thomson Reuters-Web of Science), were explored with a focus on keywords such as "energy efficiency", "efficiency gap", "barriers to energy efficiency" and "SMEs". In addition, European Directives, national academic publications and institutional sources such as the Italian Regulatory Authority for Electricity, Gas and Water (AEEGSI), and the Italian National Agency for New Technologies, Energy and Sustainable Economic Development (ENEA), were addressed to provide the context for the study. In the second step, the analysis of secondary data, mainly EU institutional publications and national research reports such as those published by ENEA, Gestore dei Servizi Energetici (GSE) etc., were used to identify possible solutions for bridging the energy efficiency gap. Based upon the research objectives, the unit of analysis is the Italian industrial SMEs.

\section{Energy efficiency and economic sustainability: a business perspective}

The international literature has repeatedly emphasised the need to consider the environmental, economic and social dimensions of sustainability (Blackburn, 2012; Boons et al., 2013; Beckmann et al., 2014). A comprehensive analysis of the implications of energy efficiency for all these different facets of sustainability (Siano, 2012) is beyond the scope of this study. Rather, this research intends to shed light on energy efficiency as a possible instrument for the economic sustainability of firms and, therefore, for their competitiveness (Liučvaitienè et al., 2013; Pons et al., 2013). First, it is necessary to clarify the concept of energy efficiency.

The scientific literature suggests various definitions and measures of energy efficiency (Patterson, 1996; Ang, 2006). The EU Directive 2006/32/ EC on energy end-use efficiency and energy provides a general definition of energy efficiency described as a ratio between an output performance and an input of energy. Depending on the research field (engineering, operations research, economics and so on), different measures of energy efficiency are used. For the purpose of this study, and from a managerial perspective, energy efficiency is described as the use of energy per unit of output (Koopmans and de Velde, 2001). Accordingly, energy efficiency can be measured using a simple average indicator, such as the ratio of energy to GDP (Khademvatani and Gordon, 2013). 
Sinergie Vol. 33, N. 96, 2015

When discussing energy costs, several scholars and professionals focus on the technological aspects and the cost of different production options, forgetting that the primary drivers of energy sustainability are the energy savings and efficiency. The two concepts are often confused, so it is useful to provide a clearer definition. A policy of energy savings implies the diffusion of a thoughtful/responsible use of the resource. This change requires, first and foremost, a new cultural approach for the developed countries, accustomed to considering energy a lowcost resource available naturally. This approach means changing some patterns of consumption. For example, powerful cars unsuited to traffic conditions, or shops keeping doors wide open in winter, are consuming energy inefficiently. Changing consumer culture is a long-term goal, requiring significant investment in communication and the consumers' education (Siano, 2012).

Conversely, energy efficiency means using technologies and tools to minimise fuel consumption, without compromising the obtained output (Panati and Golinelli, 1991), but achieving greater output from the same resources. Therefore, energy efficiency aims to save resources in different ways. An increased awareness of energy use and new behavioural patterns are important for energy efficiency for at least two reasons. First, due to the particular characteristics of the technologies of efficiency, often incremental in nature and requiring solutions on a case-by-case basis. Second, investing in energy efficiency is radically different from investing in 'classical' renewable sources, because they do not produce incremental wealth flows but reduce historical costs.

Beyond environmental and social benefits (Baccarani et al., 1993), the sustainable and efficient use of energy is particularly relevant because it affects commercial and industrial competitiveness (Khademvatani and Gordon, 2013). Faced with a continuing rise in energy prices for businesses, improving energy efficiency becomes more and more important for businesses as a way of reducing operating costs and increasing competitiveness and productivity (Backlund et al., 2012). Moreover, Worrell et al. (2003) demonstrated that, in addition to reducing energy costs, energy efficiency investments can provide core benefits, such as increased productivity.

\section{The energy efficiency gap and the barriers to energy efficiency for SMEs}

Some studies have shown the volume of output to grow faster than energy efficiency, thereby leading to increased energy consumption in firms. However, other studies argue that unexplored opportunities exist for investments in energy efficiency to reduce energy costs, thus underlining a gap of energy efficiency (Koopmans and de Velde, 2001). The energy efficiency gap is defined as the gap between actual and optimal energy use (Jaffe and Stavins, 1994). In the 20-20-20 strategy, the European Commission has estimated the technical energy-saving potentials in various sectors, which range, for example, from $25 \%$ in manufacturing, 
to $30 \%$ in commercial buildings and $26 \%$ in private households (Backlund et al., 2012). These data call for implementation rates for energy saving measures. The energy-saving potentials estimated by the European Federico Testa Vania Vigolo Sustainability through energy efficiency: Commission can be seen as estimates of the energy efficiency gap in various sectors (Backlund et al., 2012). However, scientific evidence of such high implementation rates is still scarce, in particular in the industrial sector (Thollander et al., 2013). In this sense, the energy efficiency gap has also been described as "a strategy implementation challenge" (Virkki-Hatakka et al., 2013, p. 500). As reported by Virkki-Hatakka et al. (2013), only 5-15\% of the planned strategies are fulfilled at the organizational level, hence there is a gap between energy efficiency goals and their actual implementation. Specifically, the cost effectiveness of energy efficiency measures and the measures actually implemented are very different (Backlund et al., 2012). Traditionally, the energy efficiency gap has been attributed to technology. The decision to replace a technology with a more efficient one can occur in two situations:

a) 'voluntary' replacement of current technology with a more efficient technology. The investment consists of the purchase cost of the more efficient technology.

b) 'forced' replacement, at the end of its life cycle, of the technology with a more efficient one. The investment is expressed by the differential cost of a more efficient technology, compared to the conventional technology.

However, the efficient use of energy is not only a consequence of investments in energy-efficient technologies. Improvements can also be achieved through energy management. Successful energy management can increase the energy efficiency of existing activities, but it can also overcome barriers to the diffusion of more efficient technologies, and influence investment decisions. For example, according to a recent study (Backlund et al., 2012) the energy intensity of the Swedish industry has declined. According to Martínez and Silveira (2012), this change is due not to structural changes, but rather to the effect of high energy prices, energy taxation and electricity investment and consumption.

There is no single definition of energy management in academic literature. Energy management includes the planning of investments in energy efficiency, and the care and maintenance of technology to maintain efficient operations (Gordic et al., 2010). As the industrial sector is heterogeneous, the success of energy management depends upon many factors, such as company size and type of industry (Mckeiver and Gadenne, 2005). Despite these differences, studies and definitions of energy management practices tend to provide similar steps (Abdelaziz et al., 2011):

- Analysis: energy auditing and collection of information regarding energy flows. An energy audit is usually the first step when starting business energy management;

- Reporting: quantifying the energy efficiency targets and communicating the organisation's goals. Without organisational support and an organisational culture of continuous improvement, any management system faces the risk of ineffectiveness (Rohdin and Thollander, 2006);

- Action: the implementation and maintenance of new efficiency measures. Energy management requires continuous improvement (Gordic et al., 2010). 
Sinergie Vol. 33, N. 96, 2015

According to the European Commission, the economic potential for energy efficiency in European industry is 25\% (European Commission, 2006). This means that there is a gap of $25 \%$ in energy efficiency that could be reduced by undertaking investments in technology and energy management strategies. However, research indicates that part of the energy efficiency potential remains untapped. The academic debate about the "energy efficiency gap" focuses on the reasons why profitable investments to reduce energy consumption are not realized in firms (Bunse et al., 2011). This is commonly explained by the existence of obstacles or barriers to energy efficiency (Jaffe and Stavins 1994). A barrier for energy efficiency has been described (Sorrell et al., 2000, p. 5) as "a postulated mechanism that inhibits investments in technologies that are both energy efficient and (at least apparently) economically efficient". Various studies (e.g. Hirst and Brown, 1990; Weber, 1997; Sorrell et al., 2000) have addressed barriers to energy efficiency. A number of studies have emphasized the role of financial and economic barriers to the implementation of energy efficiency measures, namely decisions based on payback periods instead of interest rate calculations, limited access to capital, as well as a low priority given to energy efficiency by the management (Bunse et al., 2011). In addition, some authors identified lack of information or difficult-to-measure components of energy investments (such as transaction or monitoring costs) as major barriers to energy efficiency (DeCanio and Watkins, 1998).

However, research about energy efficiency in small and medium enterprises (SMEs) is still limited. Recent studies (Thollander et al., 2007; Trianni and Cagno, 2012; Trianni et al., 2013) have proposed a taxonomy of barriers to efficiency for SMEs, identifying internal and external barriers. For example, internal barriers may include low capital availability, lack of interest in energy efficiency and a complex decision chain (Trianni et al., 2013), while external barriers may include energy price distortion, market risks and lack of proper regulation. This study adapts the taxonomy provided by Thollander et al. (2013), who identified four major types of barriers to energy efficiency: financial barriers, information barriers, organizational barriers, and external barriers. In the Italian context, financial barriers are particularly evident. Financial obstacles can be explained by the fact that efficiency investments do not generate additional inflows of cash or revenues, but rather cost savings, which require complex technical analyses to be properly identified (Thollander and Ottosson, 2010). In addition, financial institutions sometimes lack this type of competences. Hence, several studies of companies' investment decisions demonstrated that despite profitability, investments in energy efficiency have a low priority for cultural reasons and, in general, for informational barriers, leading to an underestimation of the importance of energy efficiency for corporate performance (DeCanio, 1998; Rohdin et al., 2007). Organisational barriers represent some behavioral aspects related to the possible divergent interests between who decides about energy efficiency and who invests. In the case of SMEs, almost all decisions, including the decisions about capital investments for energy efficiency, are made by a small board or even 
directly by the entrepreneurs themselves. Therefore, as emphasized by $\begin{gathered}\text { Federico Testa } \\ \text { Vania Vigolo }\end{gathered}$ Trianni and Cagno (2012), organisational barriers tend to fade in SMEs. Sustainability through For this reason, organisational barriers were not included in the model of an Italian perspective this study.

As to the external barriers, regulatory issues play a major role for small and medium-sized firms (Thollander et al., 2013). In certain energy systems, including the Italian one, the weight of general system costs is particularly high in energy bills. Hence, the stimulation of efficient development models which require an exemption from the quasi-fiscal component, will increase the incidence of such costs on the remaining users.

To sum up, the literature discussion shows two types of energy efficiency gap: technology and energy management (Backlund et al., 2012). These gaps can be related to different types of barriers to efficiency. From the literature review, two main types of barriers to energy efficiency can be identified, that characterise industrial SMEs: internal barriers (related to the firm) and external barriers (related to the regulatory environment).

To conclude, in this study internal barriers include economic/financial barriers and information barriers, while external barriers consists of regulatory barriers. The framework for this study is summarised in Table 1, which shows how the SMEs' overall energy efficiency gap is the result of the interaction between the above-mentioned barriers to energy efficiency, and the two dimensions of the energy efficiency gap, i.e. technology and energy management.

Tab. 1: The barriers-gap framework of energy efficiency

\begin{tabular}{|l|l|l|l|}
\hline & \multicolumn{2}{|l|}{ INTERNAL BARRIERS } & EXTERNAL BARRIERS \\
\hline & Financial & Informational & Regulatory \\
\hline Technology & $\begin{array}{l}\text { Efficiency gap 1 } \\
\text { Lack of investments } \\
\text { in energy-efficient } \\
\text { technology }\end{array}$ & $\begin{array}{l}\text { Eack of knowledge, } \\
\text { and/or low priority } \\
\text { given to investments in } \\
\text { technology and energy } \\
\text { management }\end{array}$ & $\begin{array}{l}\text { Lack of investments in technology } \\
\text { stability/initiatives to help } \\
\text { and energy management }\end{array}$ \\
\hline $\begin{array}{l}\text { Energy } \\
\text { management }\end{array}$ & $\begin{array}{l}\text { Efficiency gap 2 } \\
\text { Lackofinvestments in } \\
\text { energy management }\end{array}$ & & \\
\hline
\end{tabular}

Source: our elaboration

\section{Bridging the energy efficiency gap: an Italian perspective}

\subsection{The context of the study}

In line with the 20-20-20 targets, the Italian energy strategy (Testa and Fanelli, 2012; Ministero dello Sviluppo Economico, 2013) aims to:

- reduce greenhouse gas emissions;

- increase the use of renewable sources;

- improve energy efficiency. 
Sinergie Vol. 33, N. 96, 2015

To reach the EU: 20-20-20's primary energy savings targets, Italy's energy efficiency should increase. China is the main global investor in energy innovation, with $\$ 12.3$ billion invested ( $44 \%$ of the world), followed by the EU and the United States, with $\$ 18$ and $\$ 14.5$ billion invested, respectively. Italy, after Spain, is the European country that has invested the least in energy innovation, with a total of $\$ 1.3$ million (Istituto per la competitività I-COM, 2014). Energy efficiency is a sector that has attracted investment, with an increase of $9 \%$ over the past decade.

Although these issues have a broad impact on all stakeholders, in this study we intend to analyse the perspective of the Italian industry, with particular reference to SMEs. Specifically, energy bills for businesses in Italy are higher than the European average, with obvious consequences for the competitiveness of domestic firms.

In 2013, electricity prices for Italian companies were higher than the European average in all categories of consumption. In particular, for the categories of 500-2,000 MWh consumption, one of the most representative for the Italian market, the prices were higher than the Euro-area average of $21 \%$ for net prices, and $26 \%$ for the gross prices. The reasons for this situation can be explained by various factors, such as Italy's energy dependence, energy mix, sustainability and technical engineering of the energy mix (Testa and Vigolo, 2014). Although the analysis of these issues is beyond the scope of this study, it is necessary to point out that structural as well as internal and business-related factors influence a firm's energy efficiency. As less energy efficient means loss of competitiveness compared to Europe and other international markets, for the Italian industry, already burdened by the economic crisis and the competition from emerging countries, energy efficiency becomes a key driver to reduce costs and recover competitiveness.

The Italian energy efficiency gap has long been recognised and debated. In 2004, in a report to Italy's National Agency for Protection of the Environment, Krause (2004) stated that "Italy's economy labours under a large efficiency gap in final electricity use". Similarly, some studies conducted by the Italian National Agency for New Technologies, Energy and Sustainable Economic Development (ENEA, 2007; 2009), demonstrated the great scope of improvement in energy efficiency. With this regard, the energy-saving goal of the $20 \%$ proposed by the European Commission has been recently criticised, suggesting that the efficiency gap is even wider. For instance, the President of the European Alliance to Save Energy (EU-ASE), along with some Italian entrepreneurs, has recently urged the Italian Government to set higher goals in energy efficiency. According to EU-ASE (2015), it is possible to reduce energy consumption by $35-40 \%$ by 3030 . In addition, the European Commission identified specific areas of improvement in Energy efficiency for SMEs, namely heating, lighting, ventilation, electric motors, energy efficiency in buildings and the general requirements of energy efficiency (European Commission, 2004). 


\subsection{Bridging Italy's energy efficiency gap: possible solutions for industrial}

SMES

Through the analysis of secondary sources (mainly academic literature, European and Italian institutional publications, legislation, research reports by the Italian Regulatory Authority for the Electricity, Gas and Water and other relevant national institutions), the study proposes possible solutions to the energy efficiency gap (Table 2).

\section{Possible solutions to gap 1 (financial barriers to investments in technology)}

Low investment in energy technology by SMEs can be explained by limited financial resources and low access to credit, due to the small nature of firms. To overcome this problem, firms could collaborate to create a distributed generation. This is a type of production of electric and thermal energy aiming towards production not only for the centralised grid, but also for self-consumption at the site. Distributed generation would fit well with the structure of the Italian industry, and would minimise the distance between the site of generation and the site of energy use, thus converting the problems faced by the national electricity market into an opportunity for infrastructure development.

The legislative decree n. 115/08, which promotes energy efficiency and energy conservation, has established an "efficient system of users" that encourages investment in SMEs, with significant implications in terms of development and savings for the same firms. The system is an energy supply model for companies, consisting of on-site generation of 'virtuous' electricity (from renewable sources or cogeneration) for the direct supply of their needs. Each time a firm uses self-produced energy, direct savings on grid and system charges come as a result. Therefore, the investments can generate long-lasting effects for firms. Moreover, third parties such as the Energy Service Companies (ESCOs) can intervene with investments that enable SMEs to benefit from an efficient system of users, without having to jeopardize themselves at times of economic and financial crisis. The ESCOs could also help firms to overcome barriers to investments in technology by improving the efficiency in energy consumption in the industrial process. In particular, the ESCOs can help SMEs, that may not have the required capital or technical skills, to undertake investments in energy efficiency. Specifically, an ESCO provides the firm with the capital needed and the savings achieved will pay back the capital investment of the project. In addition, given that SMEs, and often even the ESCOs are undercapitalized, as well, a Guarantee Fund could play a key role in promoting investment in energy efficiency. The Guarantee Fund is a facility of the Ministry of Economic Development, also financed by European resources of national and inter-regional operational programs for 2007-2013, which can be activated only in respect to loans granted by banks, leasing companies and other financial intermediaries to SMEs . 


\section{sinergie}

Vol. 33, N. 96, 2015

Possible solutions to gap 2 (financial barriers to energy management)

The position of the energy manager is regulated in Italy by Law 10/91. An appointment of energy managers is compulsory for industries that consumed more than 10,000 tons of oil or an equivalent quantity over the previous year, and for all those involved in other areas that consumed more than a thousand tons. The appointment must be renewed every year, and sanctions and penalties are charged for failure to meet or for late renewal. The total energy consumption required for the production of goods or services should be evaluated separately for different energy sources, uses and end users. It is necessary to convert various sources of energy (petrol, gas, LPG, fuel oil) into a single unit of measurement: tons of oil equivalent (TOE). The energy manager's tasks include the management of energy programmes, the establishment of the investment plan following the detection of the specific objectives of energy saving and the monitoring of the implementation of the operational rationalisation (Federazione italiana per l'uso razionale dell'energia - FIRE, 2013).

Although energy managers are mandatory for big energy consumers (such as the iron and steel, textile or food industries), Italian industry consists mostly of small and medium-sized enterprises and microenterprises, for which efficient energy management is equally important as for large companies (Palm and Thollander, 2010). SMEs cannot generally afford an energy manager. The periodic use of external expertises such as an Energy Service Company (ESCO) might be considered too expensive. To overcome economic barriers to energy management, firms in the same industrial cluster may collaborate to hire a cluster energy manager. The theoretical basis of the cluster concept was proposed by Porter (1990). According to Porter (1998), an industrial cluster is a geographic cooperative group that includes suppliers, consumers, peripheral industries, governments and supporting institutions such as universities. In addition, Hill and Brennan (2000) define an industrial cluster as a system that causes component firms and institutes to generate higher unit earnings and more efficient operations, owing to innovations stimulated by intense competition and cooperation within the clusters (Belussi and Pilotti, 2002). Similarly, Anderson (1994) claimed that within an industrial cluster, various relationships exist between buyer and supplier, competitor and co-operator, who share resources. Accordingly, firms could share energy management objectives and instruments to increase efficiency, thus increasing the cluster's overall competitiveness (Nagesha, 2008). Hence, a cluster energy manager could not only advise firms individually about energy use, but also find synergies for energy management between all subjects belonging to the cluster. A common energy manager for several firms could be feasible in Italy, especially within industrial clusters, because of the types of relationships that exist between firms (Becattini and Rullani, 1993). As a matter of fact, in these contexts, both competitive and collaborative relationships coexist (Testa, 1993; Ugolini, 1995), and the latter could serve as a breeding ground for a common energy manager. 
Possible solutions to gap 3 and gap 4 (informational barriers to investments in technology and to energy management)

Federico Testa
Vania Vigolo

Sustainability through

energy efficiency:

an Italian perspective

Previous research has demonstrated that informational barriers are perceived as particularly relevant to smaller enterprises (Thollander et al., 2013). To overcome the informational barriers responsible for the efficiency gaps 3 and 4, the role of professional associations, universities, institutions and others in general research centers is extremely important. Several types of actions could be pursued by these subjects with different aims, such as raising awareness about energy efficiency, stimulating discussion about energy efficiency, and providing consultancy and support to firms. For example, in 2014 the national Italian broadcasting company (RAI) launched an informational advertisement to raise awareness about the benefits of energy savings and energy efficiency. Additionally, the GSE (Gestore dei Servizi Energetici), i.e. the state-owned company which promotes and supports renewable energy sources in Italy, is trying to reach a wider public. In particular, "GSE fosters sustainable development by providing support for renewable electricity (RES-E) generation and by taking actions to build awareness of environmentally-efficient energy uses" (www.gse.it). GSE has recently expanded its communication activities on social media such as Youtube, Twitter, LinkedIn and Slideshare, to raise awareness about energy efficiency, sharing useful information and answering possible questions and doubts about energy issues.

On the other hand, as regards consultancy and support to firms, ENEA has created a network of regional peripheral offices to provide competences and resources to local public administrations, as well as consultancy and scientific-technical support for communication campaigns aimed at informing citizens and firms about the technology and the incentives for an efficient use of energy. Further, ENEA has started a project to collect ideas and promote the discussion about sustainable development This project welcomes proposals from single firms, associations of firms or users, scholars, professional or even individual citizens. These proposals must address ENEA's core competences, i.e. energy, environment and new technologies and can attain governance, policies or new technology developments.

To overcome informational barriers, and to fill the knowledge gap between firms and efficiency-solution providers, fairs, workshops and exhibitions could play a relevant role, as well. With this regard, in 2013 the first business-to-business international exhibition on energy efficiency (Smart Energy Expo) was organised in Verona. At the exhibition, services, products and technologies for energy efficiency were presented. In addition, an Efficiency Summit with nationally and internationally renowned experts discussed the emerging trends and issues related to energy efficiency. The second edition, in 2014, attracted 120 exhibitors, 150 brands and about 9,000 professionals, including for example technology providers, ESCOs, professional associations, and energy managers.

In addition, further projects could be launched at a firm-specific level to provide information about technology energy management. For example, Unioncamere Lombardia has launched the project STEEEP - "Support and 
Sinergie Vol. 33, N. 96, 2015
Training for an Excellent Energy Efficiency Performance" to provide SMEs with tools for evaluating and improving their energy efficiency. The project involves a sample of 19 SMEs in the north of Italy (Region Lombardia) with the aim of increasing energy efficiency by $10-15 \%$ through energy management. Similarly, ENEA is promoting energy efficiency at a European level with the project "Sinergia", which aims to improve energy efficiency and environmental sustainability in SMEs' production process. This project involves a sample of 50 SMEs operating in the European agro-food industry. This aspect is particularly relevant in the energy sector because agro-food industries are among the major consumers of energy. The project promotes innovation and technology transfer though the creation of web tools for the simulations of major energy efficiency scenarios and for the life cycle cost analysis (Durajrai et al., 2002). The technology transfer is fostered through the empowerment of local help-desks addressing eco-innovation, capacity building and communications measure.

Although initiatives of this kind are still limited, they certainly represent a step forward in overcoming the informational barriers responsible for the energy efficiency gap.

Possible solutions to gap 5 and gap 6 (regulatory barriers to investments in technology and to energy management)

Policy makers could provide further regulation on several aspects that are decisive for improving energy efficiency at a firm level, and also at a wider system level, naming a few like: closed distribution systems, smart grids and energy management. Currently, the 'system charges', i.e. the costs of major incentives for renewable energy, are paid by final users' in energy bills. Although it is necessary to encourage decentralised and efficient forms of energy production, when a user does not contribute to the cost of the system, other users have to pay a higher per capita contribution. Recently, the Italian Regulatory Authority (Autorità per l'Energia Elettrica, il Gas e il Sistema Idrico (2014) made remarks to the Parliament, the Government and the Minister for Economic Development about possible distortions in competition, resulting from the current framework of the closed distribution systems (CDS, which includes the use of decentralised systems). The Under EU legislation, a Closed Distribution System operator is understood as a system which distributes electricity or gas within a geographically confined industrial, commercial or shared services site and does not supply household customers. (Article 28, Directive 2009/72/EC). The Authority claimed that the lack of development of closed distribution systems could reduce growth opportunities for the production of electricity from renewable sources and high efficiency cogeneration. Additionally, the lack of development of CDS would reduce competition for the operators of public transmission and distribution grids, and for the owners of large generating plants that convey energy produced in the public grid. As a matter of fact, in public grids of transmission and distribution, revenues are proportional to the energy that passes on the grids. Hence, the threat of a reduction in demand, due to the development of the CDS, is a powerful 
incentive for efficient management of public grids, in order to reduce the cost of transmission and dispatch, and therefore adopt more convenient CDS. However, if the subjects belonging to the CDS do not pay grid costs, Federico Testa Vania Vigolo Sustainability through energy efficiency: such lost revenues could/should be paid by grid operators, and act as an efficiency driver. Resultantly, end users would not have to pay additional charges. In this sense, if energy efficiency improves, competitiveness between energy providers increases, thus generating positive effects for the whole community.

With regard to energy management, policy makers should boost the creation of Smart Grids, i.e. an electricity network that integrates and efficiently manages the behaviour and actions of all users connected to the network (generators, consumption points, and points with both energy generation and consumption) (European Regulators' Group for Electricity and Gas - ERGEG, 2009). Accordingly, the Smart Grid's main objective is to ensure the economically efficient operation of the electrical system, with a high level of security, continuity and quality of supply (Energylab, 2011; Ceris-CNR, 2011). The Smart Grid is a network infrastructure, the primary objective of which is to support the strategy for a reliable, sustainable and competitive electricity system in a rapidly evolving energy context (European Commission, 2006). Recently, a research about smart grids was carried out by ENEA, RSE and CNR in the framework of "R\&D activities of general interest for the National Electric System", funded by the Italian Ministry of Economic Development.

Moreover, specific incentives could be identified to reward firms that surpass certain thresholds of energy efficiency (GSE, 2013). These energy savings should be measurable, and could allow access to a tax credit that could be used within three years; for example, equal to $€ 400$ for energy saved over the deductible of $5 \%$. The old approach, based on incentives to objects (plants), would be replaced by a result-based incentive approach, regardless of the mode (energy management or investment) used to achieve results. In general, policy makers should try to reduce opportunistic behaviours within the energy system.

As discussed in "Possible solutions to gap 2", in Italy, the energy manager is already compulsory for energy-intensive firms. Policy makers should foster the use of energy management competences in SMEs as well, starting from industrial clusters. In addition, a regulation that could favour the evolution and opening of clusters could also favour the diffusion of energy management. Therefore, energy efficiency would become the guiding principle of small and medium-sized enterprises. Closed distribution systems, self-consumption and smart grids are part of Italy's future National Energy Strategy. Central to the debate about future energy policy is the issue of energy efficiency, which should become the guiding principle so as to access any form of reward. Table 2 summarises the possible solutions to reduce the extended energy efficiency gap for Italian industrial SMEs. 
sinergie Vol. 33, N. 96, 2015
Tab. 2: Possible solutions to reduce the extended energy efficiency gap

\begin{tabular}{|l|l|l|l|}
\hline & \multicolumn{3}{|c|}{ Barriers to efficiency } \\
\hline & Financial & Informational & Regulatory \\
\hline Technology & $\begin{array}{l}\text { Gap 1 } \\
\text { Efficient system of } \\
\text { users } \\
\begin{array}{l}\text { ESCOs } \\
\text { Guarantee fund }\end{array}\end{array}$ & $\begin{array}{l}\text { Gap 3 and Gap 4 } \\
\text { Information activities } \\
\text { by Professional } \\
\text { associations, Public } \\
\text { institutions, Research } \\
\text { centres }\end{array}$ & $\begin{array}{l}\text { Gap 5 and Gap 6 } \\
\text { Regulation on } \\
\text { systems } \\
\text { Smart grids } \\
\text { Result-based incentives } \\
\text { Energy manager }\end{array}$ \\
\hline $\begin{array}{l}\text { Energy } \\
\text { management }\end{array}$ & $\begin{array}{l}\text { Gap 2 } \\
\text { ESCOs } \\
\text { Cluster energy } \\
\text { manager }\end{array}$ & & \\
\hline
\end{tabular}

Source: our elaboration

\section{Discussion, managerial and policy implications}

This exploratory study contributes to the development of the academic debate about energy efficiency from a SMEs' perspective. In particular, it develops a framework of analysis for the energy efficiency gap of Italian industrial SMEs, by combining the two-dimensional gap proposed by Backlund et al. (2012), with the barriers to energy efficiency (Trianni and Cagno, 2012; Thollander et al., 2013). Additionally, this study proposes a model for improving energy efficiency by bridging both the technology gap and the energy management gap. From the possible solutions provided in Table 2, it is clear that collaboration between SMEs and ESCOs, as well as collaboration between firms, e.g. those belonging to the same cluster, is crucial so as to overcome major economic/financial and informational barriers to efficiency for industrial SMEs. In addition, the role of institutions, both public (e.g. ENEA) and private (e.g. professional associations), is of uttermost importance for the creation of an energy efficiency culture and to raise awareness about this issue. Finally, policy makers should intervene both at a firm-level (e.g. with result-based incentives) and at a system level (e.g. by favouring smart grids) to increase energy efficiency for Italian SMEs.

From the analysis, it emerges that energy efficiency does not only affect firms' economic sustainability and competitiveness. The benefits of an increase in energy efficiency can be extended to the environment (through the increase of renewable sources) and to society (decentralisation of production would increase competition and reduce energy bills for households). Moreover, considering the current economic and financial crisis, an improved energy efficiency and, consequently, monetary savings could be transformed into investments in technology and innovation for the Italian industrial production. A revitalisation of the industrial production would also bring an increase in employment. It should be noted that Italy is one of five European countries whose main share of GDP is tied to industrial manufacturing. Hence, for manufacturing firms, energy efficiency plays a crucial role in competitiveness. It can be argued that energy efficiency is a key driver of reduced energy costs in industrial 
processes, ensuring greater competitiveness of the national industry, and is a crucial tool in transforming the environment, as defined by the EU level

in 2020 and 2050, into an opportunity for economic and industrial growth.

nergy efficiency:

From the analysis of Confindustria (2013), a reliable and stable regulatory

framework from 2014-2020 could contribute to the annual average growth rate of the economy by $0.5 \%$, an increase in the number of employed by 500,000 units and a cut of the national energy bill by $10 \%$ per year.

At a time when attention is aimed at identifying policies for growth, the industrial sector for energy efficiency can be important for economic recovery. Italian SMEs have the skills related to industrial plants and machinery used for energy efficiency. The government should encourage investments that activate manufacturing and employment, which would increase the innovation and the competitiveness of the Italian firms (Dervitsiotis, 2014).

\section{Limitations and further research}

Although this study provides academic and practical implications for both firms and policy makers, several limitations should be considered. First, this is a theoretical paper, hence further research (both qualitative and quantitative) should be conducted to assess firms' perspectives in relation to the proposed suggestions. Second, this study focuses on industrial SMEs in general. However, differences between types of industries (steel versus food, for example) in terms of energy use behaviour should be taken into account in further studies. Similarly, firms belonging to the same industry will probably approach energy efficiency differently, according to their dimensions. Moreover, future research could consider household and policy makers' perspectives. To conclude, energy efficiency is one of the most important challenges for firms, and broadly, for society. It has the potential to set the energy system on a more sustainable path, towards a new model of economic growth, for technological progress and social wellbeing.

\section{References}

ABDELAZIZ E.A., SAIDUR R., MEKHILEF S. (2011), "A review on energy saving strategies in industrial sector", Renewable and Sustainable Energy Reviews, vol. 15, n. 1, pp. 150-168.

ANDERSON G. (1994), "Industry clustering for economic development", Economic Development Review, vol. 12, n. 2, pp. 26-32.

ANG B.W. (2006), "Monitoring changes in economy-wide energy efficiency: from energy-gdp ratio to composite efficiency index", Energy Policy, vol. 34, pp. 574-582.

AUTORITÀ PER L'ENERGIA ELETTRICA, IL GAS E IL SISTEMA IDRICO (2014), Relazione annuale sullo stato dei servizi e sullattività svolta, vol. 1 [accessed online 30 January 2015 at]: http://www.autorita.energia.it/allegati/relaz ann/14/RAVolumeI_2014.pdf 
Sinergie Vol. 33, N. 96, 2015

BACCARANI C., GOLINELLI G.M. (2008), “The Entrepreneur and the Frontiers of Complexity”, Sinergie, n. 75, Gennaio-Aprile, pp. V-X.

BACCARANI C., TESTA F., UGOLINI M. (1993), "Le scelte competitive nell'evoluzione delle attese sociali", Sinergie, n. 31, Maggio-Agosto.

BACKLUND S., THOLLANDER P., PALM J., OTTOSSON M. (2012), "Extending the energy efficiency gap”, Energy Policy, vol. 51, pp. 392-396.

BECATTINI G., RULLANI E. (1993), "Sistema locale e mercato globale", Economia e politica industriale, n. 80, pp. 25-48.

BECKMANN M., HIELSCHER S., PIES I. (2014), "Commitment Strategies for Sustainability: How Business Firms Can Transform Trade-Offs Into WinWin Outcomes", Business Strategy and the Environment, vol. 23, n. 1, pp. 18-37.

BELUSSI F., PILOTTI L. (2002), "Learning and innovation by networking within the Italian industrial districts: the development of an explorative analytical model", Sinergie, n. 58, pp. 3-43.

BLACKBURN W.R. (2012), The Sustainability Handbook: The Complete Management Guide to Achieving Social. Economic and Environmental Responsibility, Routledge, London.

BLOMBERG J., HENRIKSSON E., LUNDMARK R. (2012), “Energy efficiency and policy in Swedish pulp and paper mills: a data envelopment analysis approach", Energy Policy, vol. 42, pp. 569-579.

BOONS F., MONTALVO C., QUIST J., WAGNER M. (2013), "Sustainable innovation. business models and economic performance: an overview", Journal of Cleaner Production, vol. 45, pp. 1-8.

BUNSE K., VODICKA M., SCHÖNSLEBEN P., BRÜLHART M., ERNST F.O. (2011), "Integrating energy efficiency performance in production management-gap analysis between industrial needs and scientific literature", Journal of Cleaner Production, vol. 19, n. 6, pp. 667-679.

CERIS-CNR (2011), Lo stato dellarte sulle smart grid: orientamenti, attori, prospettive, Rapporto Tecnico, n. 36.

CONFINDUSRIA (2013), Smart Energy Project, [accessed online 30 May 2014 at]: http://www.qualenergia.it/sites/default/files/articolo-doc/Smart\%20 Energy\%20Project_Executive\%20Summary\%2001_10_13.pdf.

CRANE A., MATTEN D. (2007), Business Ethics, 2nd ed., Oxford University Press, New York.

DECANIO S.J. (1998), “The efficiency paradox: bureaucratic and organizational barriers to profitable energy-saving investments", Energy Policy, vol. 26, n. 5, pp. 441-454.

DECANIO S.J., WATKINS W.E. (1998), "Investment in energy efficiency: do the characteristics of firms matter?", Review of economics and statistics, vol. 80, n. 1, pp. 95-107.

DERVITSIOTIS K.N. (2014), "Cultivating total innovation for operational and adaptation excellence", Sinergie, n. 93, pp. 19-31.

DURAIRAJ S.K., ONG S.K., NEE A.Y., TAN R.B. (2002), "Evaluation of life cycle cost analysis methodologies", Corporate Environmental Strategy, vol. 9, n. 1, pp. 30-39.

ENEA (2007), Rapporto energia e ambiente 2006.

ENEA (2008), Rapporto energia e ambiente 2009.

ENEA (2014), Rapporto annuale efficienza energetica 2012. 
ENERGY LAB (2011), Le Smart Grid per la gestione flessibile della domanda elettrica, Ceced, Milano.

EU-ASE (2015), Letter to J.C. Juncker [accessed online 30 January 2014 at]: http:// www.kyotoclub.org/docs/20140716_eu-ase_letter_to_president_juncker. pdf

EUROPEAN COMMISSION (2004), EMAS Energy Efficiency Toolkit for Small and Medium sized Enterprises, [accessed online 30 May 2014 at]: http:// ec.europa.eu/environment/emas/pdf/general/energyeff_en.pdf

EUROPEAN COMMISSION (2006), Directive 2006/32/EC.

EUROPEAN COMMISSION (2006), European Smart Grids Technology Platform. Vision and Strategy for Europe's Electricity Networks of the Future, Brussels.

EUROPEAN COMMISSION, Directive 2009/72/EC.

EUROPEAN COMMISSION, Directive 2012/27/EU.

EUROPEAN COMMISSION, Energy Efficiency Plan 2011.

EUROPEAN ENVIRONMENT AGENCY (2013), Trends and projections in Europe 2013 Tracking progress towards Europe's climate and energy targets until 2020.

EUROPEAN REGULATORS' GROUP FOR ELECTRICITY AND GAS (2009), "Position Paper on Smart Grids", ERGEG public consultation paper - 10 December.

FEDERAZIONE ITALIANA PER L'USO RAZIONALE DELL'ENERGIA - FIRE (2013), Rapporto sugli Energy Manager in Italia: evoluzione del ruolo e statistiche, [accessed online 30 May 2014 at]: http://em.fire-italia.org/wpcontent/uploads/2014/01/2013-11-rapporto-evoluzione-energy-manager. pdf.

GILL J., JOHNSON P. (1991), Research Methods for Managers, Paul Chapman Publishing, London.

GORDIĆ D., BABIĆ M., JOVIČIĆ N., ŠUŠTERŠIČ V., KONČALOVIĆ D. JELIĆ D. (2010), "Development of energy management system-Case study of Serbian car manufacturer", Energy Conversion and Management, vol. 51, n. 12, pp. 2783-2790.

GREGOR S. (2006), "The nature of theory in information systems", MIS Quarterly, vol. 30, n. 3, pp. 611-642.

GSE (MONTANINO G.), "Stato attuale: analisi e governance dellefficienza energetica", Verona Efficiency Summit, 9 ottobre 2013.

HILL E.W., BRENNAN J.F. (2000), "A methodology for identifying the drivers of industrial clusters: the foundation of regional competitive advantage", Economic Development Quarterly, vol. 14, n. 1, pp. 65-96.

HIRST E., BROWN M. (1990), "Closing the efficiency gap: barriers to the efficient use of energy", Resources, Conservation and Recycling, vol. 3, n. 4, pp. 267281.

ISTITUTO PER LA COMPETITIVITÀ (I-COM), (2014), Rapporto I-Com 2014 sull'innovazione energetica, retrive from http://www.i-com.it/wp-content/ uploads/2014/05/rapporto_i-com_2014_sull_innovazione_energetica.pdf, 30

JAFFE A.B., STAVINS R.N. (1994), “The energy-efficiency gap. What does it mean?”, Energy policy, vol. 22, n. 10, pp. 804-810.

KHADEMVATANI A., GORDON D.V. (2013), "A marginal measure of energy efficiency: The shadow value", Energy Economics, n. 38, pp. 153-159.
Federico Testa
Vania Vigolo

Sustainability through

energy efficiency:

an Italian perspective 
sinergie Vol. 33, N. 96, 2015

KOOPMANS C.C., TE VELDE D.W. (2001), "Bridging the energy efficiency gap: using bottom-up information in a top-down energy demand model", Energy economics, vol. 23, n. 1, 57-75.

KRAUSE F. (2004), The potential for more efficient electricity use in Italy, Report to Agenzia Nazionale per la Protezione dell'Ambiente, Rome.

LIUČVAITIENE A., PELECKIS K., SLAVINSKAITĖ N., LIMBA T. (2013), "Theoretical Models of Business Competitiveness: Formation and Evaluation", Strategic Management Review, vol. 1, n. 1, pp. 31-44.

MARTÍNEZ C.I., SILVEIRA S. (2012), "Analysis of energy use and CO2 emission in service industries: Evidence from Sweden", Renewable and Sustainable Energy Reviews, vol. 16, n. 7, pp. 5285-5294.

MCKEIVER C., GADENNE D. (2005), "Environmental management systems in small and medium businesses", International Small Business Journal, vol. 23, n. 5, pp. 513-537.

MINISTERO DELLO SVILUPPO ECONOMICO (2013), Strategia Energetica Nazionale: per unienergia più competitiva e sostenibile 1 [accessed online 30 January 2015 at]: http://www.sviluppoeconomico.gov.it/images/ stories/normativa/20130314_Strategia_Energetica_Nazionale.pdf.

NAGESHA N. (2008), "Role of energy efficiency in sustainable development of small-scale industry clusters: an empirical study", Energy for Sustainable Development, vol. 12, n. 3, pp. 34-39.

PALM J., THOLLANDER P. (2010), "An interdisciplinary perspective on industrial energy efficiency", Applied Energy, vol. 87, n. 10, pp. 3255-3261.

PANATI G., GOLINELLI G.M. (1991), Tecnica economica industriale $e$ commerciale, La Nuova Italia Scientifica, Roma.

PATTERSON M.G. (1996), "What is energy efficiency? Concepts, indicators, and methodological issues”, Energy Policy, vol. 24, pp. 377-390.

PONS M., BIKFALVI A., LLACH J., PALCIC I. (2013), "Exploring the impact of energy efficiency technologies on manufacturing firm performance", Journal of Cleaner Production, vol. 52, pp. 134-144.

PORTER M.E. (1990), “The competitive advantage of nations”, Harvard Business Review, March-April, pp. 73-93.

PORTER M.E. (1998), “Clusters and the new economics of competition”, Harvard Business Review, vol. 76, n. 6, pp. 77-90.

ROHDIN P., THOLLANDER P. (2006), "Barriers to and driving forces for energy efficiency in the non-energy intensive manufacturing industry in Sweden", Energy, vol. 31, n. 12, pp. 1836-1844.

ROHDIN P., THOLLANDER P., SOLDING P. (2007), "Barriers to and drivers for energy efficiency in the Swedish foundry industry”, Energy Policy, vol. 35, n. 1, pp. 672-677.

SIANO A. (2012), "La comunicazione per la sostenibilità nel management delle imprese", Sinergie, n. 89, pp. 3-23.

SORRELL S., SCHLEICH J., SCOTT S., O’MALLY E., TRACE F., BOEDE U., OSTERTAG K., RADGEN P. (2000), Reducing barriers to energy efficiency in public and private organizations, Science and Policy Technology Research (SPRU), University of Sussex, Sussex, UK.

TESTA F. (1993), Le dinamiche competitive nel settore della calzetteria femminile, Cedam, Padova. 
TESTA F., FANELLI T. (2012), "A proposito di strategia energetica nazionale", Economics and Policy of Energy and the Environment, I quadrimestre, pp. $19-41$.

Federico Testa
Vania Vigolo

Sustainability through

energy efficiency:

an Italian perspective

TESTA F., VIGOLO V. (2014), "Sostenibilità ambientale, tecnico ingegneristica, economica: la nuova sfida per il sistema energetico italiano", Management delle utilities e delle infrastrutture, n. 3, pp. 12-18.

THOLLANDER P., BACKLUND S., TRIANNI A., CAGNO E. (2013), "Beyond barriers-A case study on driving forces for improved energy efficiency in the foundry industries in Finland, France, Germany, Italy, Poland, Spain, and Sweden", Applied Energy, vol. 111, pp. 636-643.

THOLLANDER P., DANESTIG M., ROHDIN P. (2007), "Energy policies for increased industrial energy efficiency: evaluation of a local energy program for manufacturing SMEs”, Energy Policy, vol. 35, n. 11, pp. 5774-5783.

THOLLANDER P., OTTOSSON M. (2008), "An energy-efficient Swedish pulp and paper industry - exploring barriers to and driving forces for cost-effective energy efficiency investments", Energy Efficiency, vol. 1, n. 1, pp. 21-34.

TRIANNI A., CAGNO E. (2012), "Dealing with barriers to energy efficiency and SMEs: some empirical evidences", Energy, vol. 37, n. 1, pp. 494-504.

TRIANNI A., CAGNO E., WORRELL E., PUGLIESE G. (2013), "Empirical investigation of energy efficiency barriers in Italian manufacturing SMEs", Energy, vol. 49, pp. 444-458.

UGOLINI M. (1995), La natura dei rapporti tra imprese nel settore delle calze per donna, Cedam, Padova.

VIRKKI-HATAKKA T., LUORANEN M., IKÄVALKO M. (2013), "Differences in perception: How the experts look at energy efficiency (findings from a Finnish survey", Energy Policy, vol. 60, pp. 499-508.

WEBER L. (1997), "Some reflections on barriers to the efficient use of energy", Energy Policy, vol. 25, n. 10, pp. 833-835.

WORRELL E., LAITNER J.A., RUTH M., FINMAN H. (2003), "Productivity benefits of industrial energy efficiency measures", Energy, vol. 28, n. 11, pp. 1081-1098.

\section{Academic or professional position and contacts}

Federico Testa

Full Professor of Management

University of Verona, Italy

e-mail: federico.testa@univr.it

\section{Vania Vigolo}

$\mathrm{PhD}$, Researcher of Management

University of Verona, Italy

e-mail: vania.vigolo@univr.it

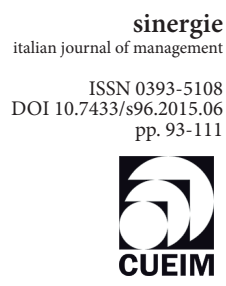

